\title{
Phase Shifting Transformer-LCL (PST-LCL) Filter: Modeling and Analysis
}

\author{
Mohammad Amin Chitsazan*, Andrzej M Trzynadlowski \\ Department of Electrical and Biomedical Engineering, University of Nevada, Reno, USA \\ Email address: \\ chitsaazaan@gmail.com(M. A. Chitsazan), chin@unr.edu (A. M. Trzynadlowski) \\ ${ }^{*}$ Corresponding author
}

\section{To cite this article:}

Mohammad Amin Chitsazan, Andrzej M Trzynadlowski. Phase Shifting Transformer-LCL (PST-LCL) Filter: Modeling and Analysis. American Journal of Electrical Power and Energy Systems. Vol. 7, No. 1, 2018, pp. 1-10. doi: 10.11648/j.epes.20180701.11

Received: February 14, 2018; Accepted: March 5, 2018; Published: March 27, 2018

\begin{abstract}
Power converters have been widely used in power systems to improve the quality and magnitude of the power drawn from renewable energy sources. An LCL filter for connection of an inverter to the grid is often used to reduce the harmonics generated by the inverter. Based on the different design methodologies, optimal parameters of LCL filters tend to differ in wide ranges. This paper proposes a new approach to an LCL filter used for decreasing the harmonic currents. A phase shifting transformer is added into the structure of an LCL filter to mitigate the harmonic current. The procedures and techniques described in this paper are particularly suitable for the grid-connected photovoltaic energy systems.
\end{abstract}

Keywords: LCL Filters, Phase Shifting Transformers, PV Systems, Total Harmonic Distortion

\section{Introduction}

There is a growing demand for high-quality and reliable electrical energy and protection systems have a significant impact on improvement of the system reliability [1-2]. Energy systems based on photovoltaic (PV) cells have been growing with a fast pace. Typically, they are connected to the grid through multilevel voltage source inverters [3]-[5]. To mitigate the harmonic content of the output current, a filter is required between the inverter and the power grid. The simplest solution is to use an inductor, but its huge size and significant voltage drop are disadvantageous [6].

Therefore, an LCL passive filter is employed to mitigate current harmonics caused by pulse width modulation (PWM) at the point of common coupling (PCC). Compared by a firstorder L filter, the LCL filters meet the standards for grid interconnection with smaller size and cost, particularly in high-power cases [7]. Higher attenuation and cost savings due to the weight and size reduction are additional advantages. References [8] and [9] discuss application of LCL filters in grid-connected inverters and PWM rectifiers, where the amount of current distortion injected into the utility grid is minimized. But, certain control difficulties may arise. The LCL filter may cause instability of a closed-loop control system, and trigger resonances between the inverter and the grid.

Harmonic attenuation by the LCL filter results in lower switching frequencies necessary for meeting harmonic constraints, as defined by standards such as IEEE-519 [10], and IEEE-1547 [11]. An appropriate mathematical model must be developed to design the filter effectively. Suggested solutions include parameter choice to suppress possible resonances in the filter [12]-[13], active damping [14-16], passive damping [17-8], and state feedback control with state observer [18].

Passive damping method, a simple, effective, and reliable solution, is implemented by inserting a resistor in series with the capacitor in the filter. However, it causes extra power loss and deteriorates the high-frequency harmonic attenuation ability of the filter. Adding an RC circuit in parallel with the capacitor of the filter is considered an effective means to overcome this problem.

However, the high-frequency harmonic attenuation of the passively damped LCL filter deteriorates when compared with an undamped filter. Stability study of a system with the LCL filter is described in [19] and current control techniques in the LCL filter design are reviewed in [20].

This paper contains a comprehensive analysis and modeling of a phase shifting transformer (PST). The 
objective is to optimize its design for minimizing the total harmonic distortion (THD) of the filtered current. The PST is inserted in series with the capacitor. The phase angle of the PST makes the filter controllable. Adjusting the phase angle of the PST allows significant reduction of the THD. The PST can also be used for harmonic mitigation, with no need for adjustment of the LCL parameters, when the switching frequency of the inverter changes.

The paper is organized as follows. Characteristics of the PST are discussed in Section 2. The proposed filter is presented in Section 3. Filter design procedure is briefly explained in detail in Section 4. Simulation of two case studies are described in Section 5, and Section 6 concludes the considerations.

\section{Phase shifting Transformer}

PSTs allow an economical and reliable control of electricity transfer over parallel conduits of electricity, e.g., an overhead transmission line and an underground cable [2125]. The power flow is controlled by changing the phase-shift angle between the PST source- and load-side voltages [26]. PSTs are installed or are planned for installation in various areas [27]. The PST can be modeled as a reactance in series with a phase shift, as illustrated in Figure 1. The active power passing through a line is a function of the phase angle $\alpha$. However, in many cases the angles are controlled by humans. Reference [28] presents a method to control the phase angle by a voltage source converter (VSC). Furthermore, variations of the phase angle are carried out by adding a regulated quadrature voltage to the source's line-to-neutral voltage [29]. This paper shows that harmonic currents and the THD can be adjusted by changing the phase angle of the PST.

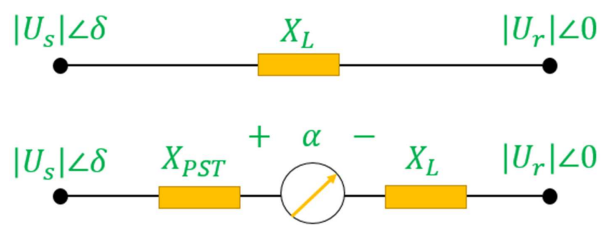

Figure 1. Models of a transmission line without and with a PST.

\section{Proposed Filter}

The proposed LCL filter is shown in Figure 2, where $L_{I}$ is the inverter side inductor, $L_{G}$ is the grid-side inductor, $C_{f}$ is a capacitor with a series $R_{f}$ damping resistor, $R_{1}$ and $R_{2}$ are inductors' resistances, and $V_{I}$ and $V_{G}$ are the inverter and grid voltages. The inverter output current, the capacitor current, and the grid current are denoted by $i_{I}, i_{c}$ and $i_{G}$, respectively.

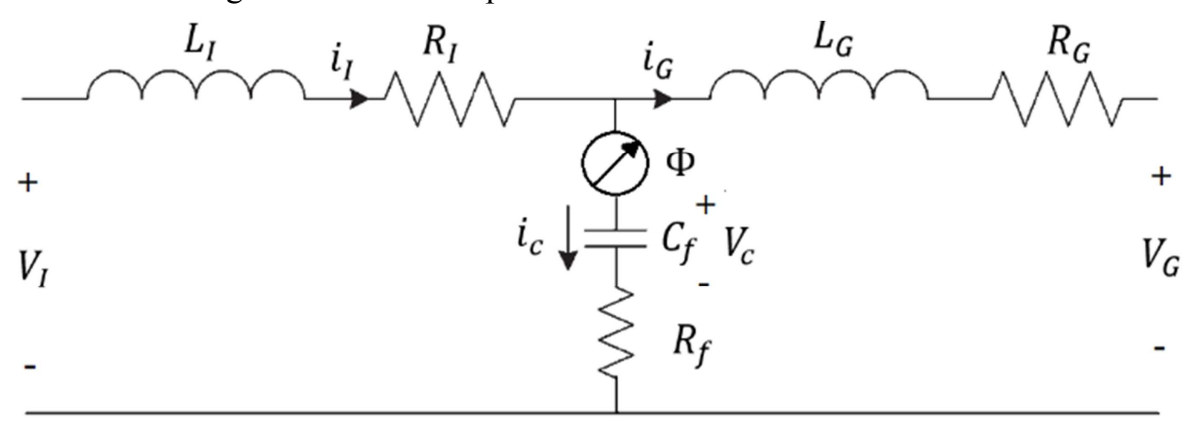

Figure 2. The proposed LCL filter (PST-LCL).

The per-phase model of the PST-LCL filter state-space model is

$$
\begin{gathered}
\frac{d V_{c}}{d t}=\frac{i_{I}-i_{G}}{C_{f}} \\
\frac{d i_{I}}{d_{t}}=\frac{1}{L_{I}} \cdot\left(V_{I}-V_{c}-R_{f} \cdot\left(i_{I}-i_{G}\right)-R_{I}, i_{I}\right) \\
\frac{d i_{G}}{d_{t}}=\frac{1}{L_{G}} \cdot\left(V_{c}+R_{f} \cdot\left(i_{I}-i_{G}\right)-V_{G}-R_{G} \cdot i_{G}\right) \\
{\left[\begin{array}{c}
\frac{d i_{I}}{d t} \\
\frac{d i_{G}}{d t} \\
\frac{d V_{c}}{d t}
\end{array}\right]=\left[\begin{array}{ccc}
\frac{-R_{f} \angle \Phi-R}{L_{I}} & \frac{R_{f} \angle \Phi}{L_{I}} & \frac{-1 \angle \Phi}{L_{I}} \\
\frac{R_{f} \angle \Phi}{L_{G}} & \frac{R_{f} \angle \Phi-R_{G}}{L_{G}} & \frac{1 \angle \Phi}{L_{G}} \\
\frac{1}{C_{f}} & \frac{1}{C_{f}} & 0
\end{array}\right] \times\left[\begin{array}{c}
i_{I} \\
i_{G} \\
V_{c}
\end{array}\right]+\left[\begin{array}{cc}
\frac{1}{L_{I}} & 0 \\
0 & \frac{1}{L_{G}} \\
0 & 0
\end{array}\right] \times\left[\begin{array}{c}
V_{I} \\
V_{G}
\end{array}\right]}
\end{gathered}
$$

An important transfer function is $H_{L C L}=\frac{i_{G}}{V_{I}}$, where the grid voltage is assumed to be an ideal voltage source capable of damping all the harmonic frequencies. If one sets $v_{G}=0$, which implies a current-controlled inverter, the transfer functions of the $L C L$ filter without and with the damping resistor are, respectively

$$
H_{L C L}(s)=\frac{1}{L_{I} \cdot C_{f} \cdot L_{G} \cdot s^{3}+\left(L_{I}+L_{G}\right) \cdot s}
$$




$$
H_{L C L}(s)=\frac{C_{f} \cdot R_{f} \cdot s+1}{L_{I} \cdot C_{f} \cdot L_{G} \cdot s^{3}+C_{f} \cdot\left(L_{1}+L_{2}\right) \cdot R_{f} \cdot s^{2}+\left(L_{I}+L_{G}\right) \cdot s}
$$

Transfer functions of the PST-LCL without and with the damping resistor are, respectively

$$
H_{P S T-L C L}(s)=\frac{1}{L_{I} \cdot C_{f} \cdot L_{G} \cdot S^{3} \angle \Phi+\left(L_{I}+L_{G}\right) \cdot s}
$$

$$
H_{P S T-L C L}(s)=\frac{C_{f} \cdot R_{f} \cdot s+1}{L_{I} \cdot C_{f} \cdot L_{G} \cdot s^{3} \angle \Phi+C_{f} \cdot\left(L_{1}+L_{2}\right) \cdot R_{f} \cdot s^{2}+\left(L_{I}+L_{G}\right) \cdot s}
$$

Bode plots of the PST-LCL filter for different phase angles are shown in Figure 3. The insertion of a phase shifting transformer eliminates the gain spike, smoothing the overall response and rolling-off between $-75^{\circ}$ and $-325^{\circ}$, instead of the $-180^{\circ}$ at high frequencies.

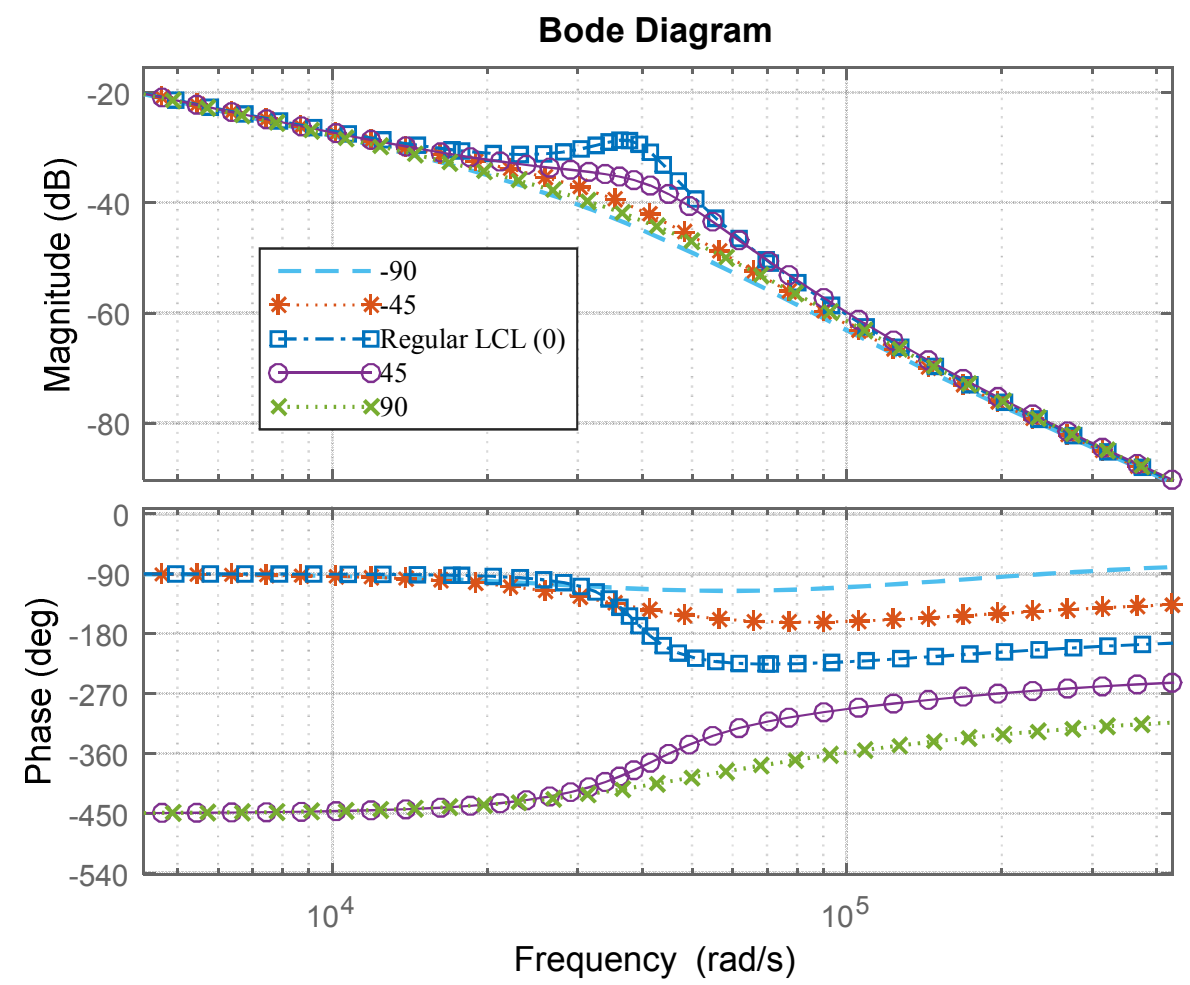

Figure 3. Bode plots of PST-LCL for different phase shifts.

\section{Filter design Procedure}

When designing an LCL filter, several specifications, such as the filter size, switching ripple attenuation [30], maximum current ripple, or phase of the parallel capacitor branch on the filter, must be considered. Passive or active damping is often placed in series with the capacitor to prevent potential resonances of the capacitor interacting with the grid, and caused by reactive power requirements. The passive and active damping have been described in [6] and [31], respectively. Data needed for the filter design are listed in Table 1.

Table 1. The parameters for designing the filter.

\begin{tabular}{ll}
\hline$V_{L L}$ & Line-to-line RMS voltage (inverter output) \\
$V_{p h}$ & Phase voltage (inverter output) \\
$P_{n}$ & Rated active power \\
$V_{d c}$ & DC-link voltage \\
$f_{g}$ & Grid frequency \\
$f_{s w}$ & Switching frequency \\
$f_{r e s}$ & Resonance frequency \\
\hline
\end{tabular}

The base impedance and capacitance are calculated as $Z_{b}=E_{n}^{2} / P_{n}$ and $C_{b}=1 /\left(\omega_{g} \cdot Z_{b}\right)$, where $P_{n}$ is the rated active power absorbed by the converter, $E_{n}$ is the line to line rms voltage, and $\omega_{n}$ is the grid frequency. Also, $\omega_{\text {res }}=$ $k \omega_{s w}$, where $\omega_{\text {res }}$ and $\omega_{s w}$ are the resonance frequency and switching frequency respectively. Coefficient $k$ represents the ratio of these two frequencies. The filter values will hence be referred to as a percentage of the base values.

It is assumed that the maximum power factor variations seen by the grid do not exceed $5 \%$. It means that the base impedance of the system is set to $5 \%$ of the base capacitor. This design factor implies that if that $5 \%$ is exceeded than compensation of the inductive reactance of the filter is necessary.

A simplified circuit of the inverter shown in Figure 4 is employed for the design of the inverter-side inductor [32]. Relations (10)-(11) and (12)-(15) below apply to a single phase and three phase cases, respectively [33]-[7]. 


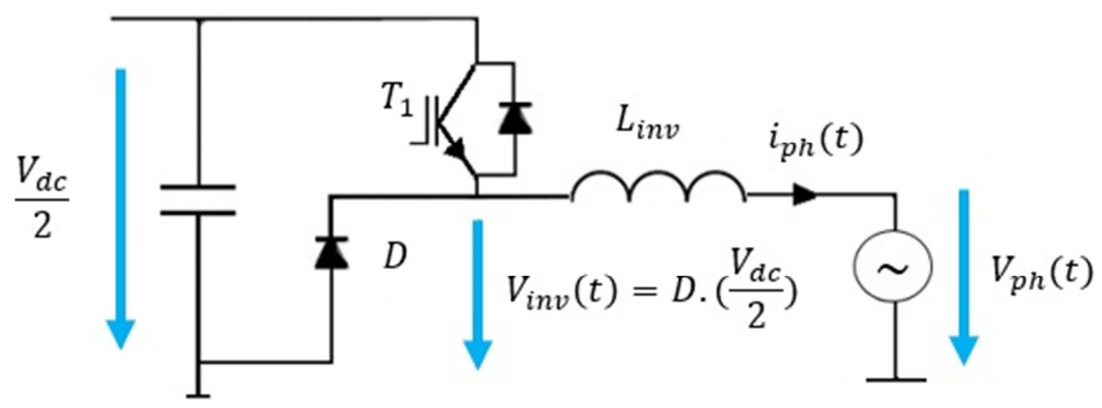

Figure 4. Simplified circuit of an inverter.

$$
\begin{aligned}
& L_{I}=\frac{\frac{V_{d c}}{2}(1-m)}{2 . \Delta I_{L_{\max }}} \cdot \frac{m}{f_{S w}} \\
& L_{I}=\frac{\frac{V_{d c}}{2}-\frac{V_{d c}}{4}}{2 . \Delta I_{L_{\max }}} \cdot \frac{1}{2 \cdot f_{s w}}=\frac{V_{D C}}{16 f_{s w} \Delta I_{L_{\max }}} \\
& \Delta I_{L_{\max }}=\frac{2 V_{d c}}{3 L_{I}}(1-m) m T_{s w} \\
& \Delta I_{L_{\max }}=\frac{V_{d c}}{6 \cdot f_{s w} \cdot L_{I}} \\
& \mathrm{I}_{\max }=\frac{P_{n} \sqrt{2}}{3 V_{p h}} \\
& \mathrm{~L}_{\mathrm{I}}=\frac{V_{d c} \cdot V_{p h}}{2 \sqrt{2} \cdot f_{s w} \cdot P_{n}}
\end{aligned}
$$

It can be seen that the maximum peak-to-peak current ripple occurs at $m=0.5$. The maximum per-unit ripple can be assumed between $5 \%$ and $25 \%$. Let the ripple be $10 \%$ of the rated current, that is, $\Delta I_{L_{\max }}=0.1 I_{L_{\max }}$. Then, $L_{I}$ can be found from (15), where $V_{d c}$ is the dc-link voltage; $f_{s w}$ is the switching frequency, and $V_{p h}$ is the phase voltage. The total inductance should be less than 0.1 p.u, because it causes a drop of the ac voltage. Otherwise, a higher dc-link voltage would be required, resulting in higher switching losses. The LCL filter should reduce the expected current ripple to $20 \%$, resulting in a ripple value of $2 \%$ of the output current [10], [34].

In order to calculate the ripple reduction, the equivalent circuit of LCL filter is initially analyzed considering the inverter as a current source for each harmonic frequency. Equation (16) below gives the relation between the harmonic current generated by the inverter and the one injected in the grid (respectively $i_{I}(h)$ and $i_{G}(h)$ ). Simplifying this equation, results in (17) that represents the ripple attenuation factor. Equations (17) and (18) relate the harmonic current generated by the inverter with the one injected to the grid. Here, $x$ is the maximum power factor variation seen by the grid, $k_{\mathrm{a}}$ is the desired attenuation, and the constant $r$ is the ratio between the inductance at the inverter side and the one at the grid side, i.e., $L_{G}=r L_{I}$. The transfer function of the filter at a particular resonant frequency can be evaluated by plotting the results for several values of $r$, depending on the nominal grid impedance [35].

$$
\frac{i_{G}(h)}{i_{I}(h)} \approx \frac{z_{L C}^{2}}{\left|\omega_{r e s}^{2}-\omega_{s w}^{2}\right|}
$$

$$
\begin{gathered}
\frac{i_{G}(h)}{i_{I}(h)}=\frac{1}{\left|1+r\left[1-L_{I} \cdot C_{b} \cdot \omega_{s w}^{2} \cdot x\right]\right|} \\
L_{G}=\frac{\sqrt{\frac{1}{k_{a}^{2}}}+1}{C_{f} \cdot \omega_{s w}^{2}}
\end{gathered}
$$

For effective attenuation, damping is needed as the transfer function of the filter peaks at certain frequencies, which may increase the ripple [32]. The resonant frequency can be calculated from formula (19) below, and it should be between ten times the grid frequency and a half of the switching frequency as stated in (20) to avoid resonance problems. Here, $f_{g}$ is the grid frequency, $f_{\text {res }}$ is the resonant frequency, and $f_{s w}$ is the switching frequency. To avoid the resonance, a damping resistance (passive damping) added in series with the capacitor attenuates part of the ripple at the switching frequency. One third of the impedance of the filter capacitor at the resonant frequency can be taken as the damping resistance $R_{f}$ [36].

$$
\begin{aligned}
f_{\text {res }} & =\frac{1}{2 \pi} \sqrt{\frac{L_{I}+L_{G}}{L_{I} \cdot L_{G} \cdot C_{f}}} \\
\text { 10. } f_{G} & <f_{\text {res }}<0.5 f_{\text {sw }} \\
R_{f} & =\frac{1}{3 \omega_{\text {res }} \cdot C_{f}}
\end{aligned}
$$

In this section, a PST inserted in series into the $R_{f}-C_{f}$ branch is considered. PSTs have been used to decrease the THD. For example, references [37] and [38] illustrate how a specific set of phase shifts can minimize, and even eliminate, specified low-order harmonics of the input current, the fifth harmonic in particular. A PST, which improves the input power factor and reduces the THD of the input current is presented in [39]. A harmonic mitigation strategy centered on the idea of two PSTs whose phase angles differ by $30^{\circ}$ is described in [40]. A variety of line-frequency PSTs for reduction of harmonics generated by nonlinear loads in electric power distribution systems is outlined in [41]. However, these transformers suffer from the large size and weight.

In this paper, the PST is employed to minimize the filter impedance at the switching frequency. Figure 5 shows the simplified circuit of the proposed LCL filter, where $I_{h}$ is the harmonic current (assumed to be less than $5 \%$ of the main current), $\Phi$ is the phase-angle difference between $I_{h}$ and the grid voltage, and $\theta$ is the phase angle of the PST. 


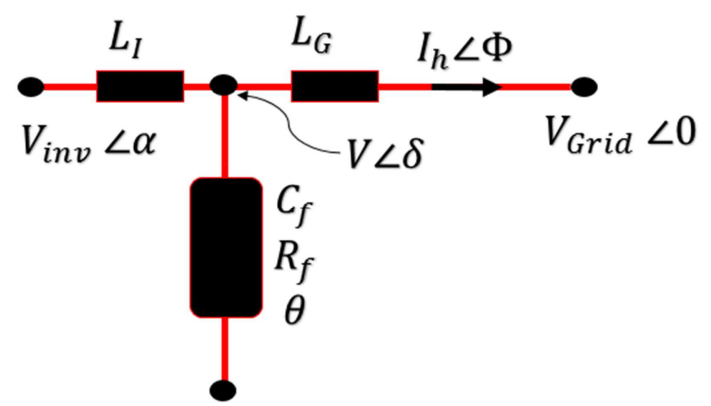

Figure 5. Simplified circuit of the proposed LCL filter.
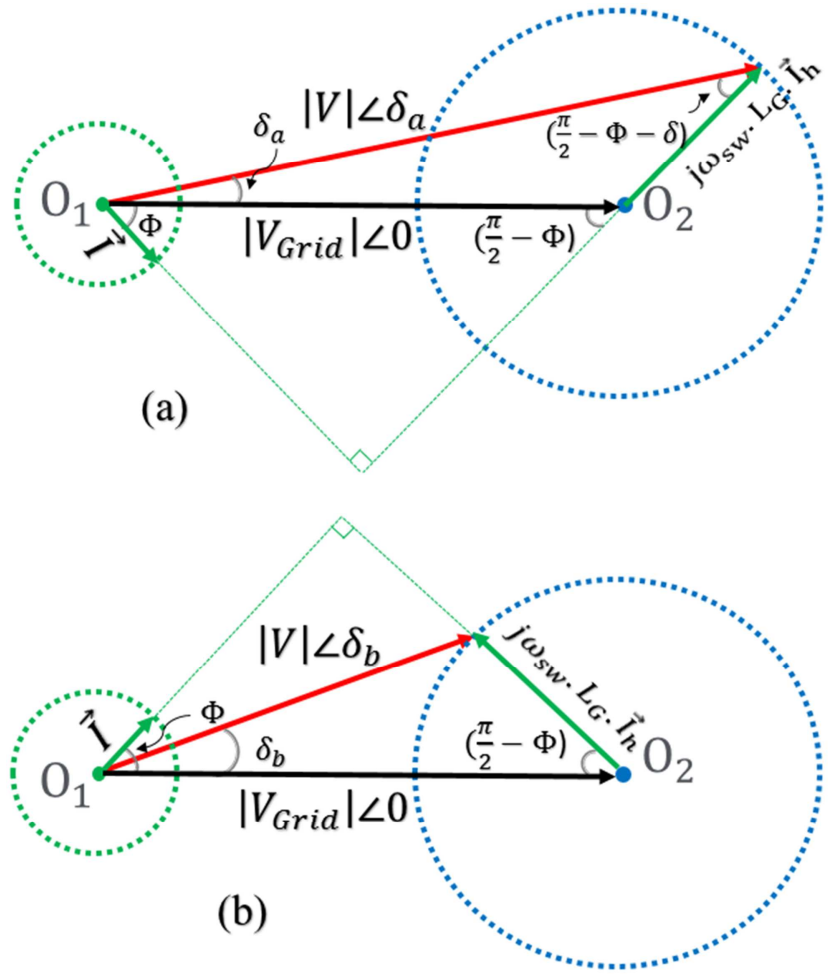

Figure 6. Phasor diagrams of the LCL filter at the switching frequency: (a) lagging current, (b) leading current.

Figure 6 shows phase diagrams for different phase angles at the switching frequency. The goal is to minimize harmonic currents at the switching frequency. As can be seen, equations (22) and (23) define the phase angle, $\delta$, between $V$ and $V_{\text {Grid }}$ caused by the harmonic currents at the switching frequency.

$$
\begin{aligned}
& \delta_{a}=\cot ^{-1}\left(\frac{\left|V_{G r i d}\right|}{\omega_{s w} \cdot L_{G} \cdot\left|I_{h}\right|} \cdot \sec (\Phi)+\tan (\Phi)\right) \\
& \delta_{\mathrm{b}}=\cot ^{-1}\left(\frac{\left|V_{G r i d}\right|}{\omega_{s w} \cdot L_{G} \cdot\left|I_{h}\right|} \cdot \sec (\Phi)-\tan (\Phi)\right)
\end{aligned}
$$

To reach the above goal, the phase angle of the phase shifter transformer, $\theta$, should be optimized. The phase angle of the voltage across the $R_{f}-C_{f}$ branch should be the same as the phase angle of the impedance of that branch. Thus, the phase shift $\theta$ of the PST should equal the difference of the phase angle of the $C_{f}-R_{f}$ branch and the phase angle of $\mathrm{V}$. Consequently, the optimum value of $\theta$ is given by

$$
\theta=-\tan ^{-1} \frac{1}{R_{f} \cdot C_{f} \cdot \omega_{s w}}-\cot ^{-1}\left(\frac{\left|V_{G r i d}\right|}{\omega_{s w} \cdot L_{G} \cdot I_{h}} \sec (\Phi) \pm \tan (\Phi)\right)
$$

\section{Simulation Results}

In this section, two case studies are presented for a singlephase inverter and a three-phase inverter. In each case, the performance of the LCL filter and the proposed filter to mitigate the harmonic currents are compared.

\subsection{Case Study A}

Figure 7 illustrates Case Study A. The 14 Trina TSM250PA05.08 solar arrays have the rated power of $3500 \mathrm{~W}$. Specifications of the arrays are listed in Table 2. There are two $4 \mathrm{nF}$ stray capacitances right after the arrays. The DC voltage is then stabilized in a DC link and feeds the VSI. Bipolar PWM was employed. The voltage of the grid is 240 $\mathrm{V}$ and the load is $10 \mathrm{~kW} / 4 \mathrm{kVAr}$. Simulink software was used to simulate the proposed filter [42].

\section{Inverter Control}

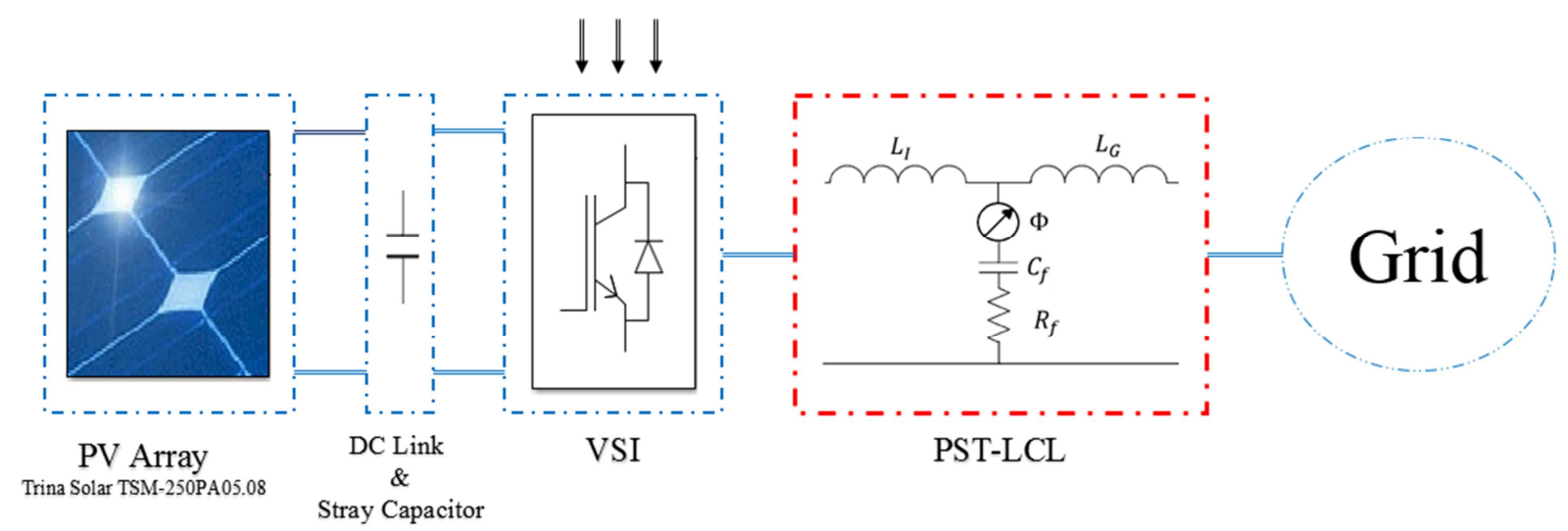

Figure 7. System in Case Study A.

Other data of the systems are: the rated active power $P_{S}=P_{n}=3.5 \mathrm{~kW}, E_{n}=240 \mathrm{~V}$, dc-link voltage $V_{D C}=$ 
$425 \mathrm{~V}$, switching frequency $f_{s w}=3780 \mathrm{~Hz}$, grid radian frequency $\omega_{g}=2 \pi .60 \mathrm{rad} / \mathrm{s}$, maximum power variation seen by the grid $x=0.05$, and attenuation factor $\mathrm{k}_{\mathrm{a}}=0.2$. Consequently, the base impedance and capacitance are $Z_{s}=16.45 \Omega$, and $C_{s}=161.2 \mu F$. Assuming a $10 \%$ allowed ripple, Eq. (15) yields $L_{I}=4.81 \mathrm{mH}$. The maximum capacitance is $8 \mu \mathrm{F}$ in order to be within the $5 \%$ limit of the base value of $C_{b}$. For the desired attenuation $k_{a}=20 \%, L_{G}$ is found from Eq. (18) to be $1.33 \mathrm{mH}$. For the calculated parameters of $L_{I}, C_{f}$, and $L_{G}$, Eq. (19) gives $f_{\text {res }}=1743$ $\mathrm{kHz}$, which meets condition (20). Eq. (21) yields the damping resistance $R_{f}=3.8 \Omega$. Finally, $\Phi$ is $3.2^{0}$, which makes $\delta_{a}=5.67^{0}$. The phase angle of the $C_{f}-R_{f}$ branch is $-54.17^{0}$ so, from Eq. (24), the phase angle of the phase shifting transformer is $-59.84^{\circ}$. Figure 8 shows waveforms and FFTs of currents injected into grid by the LCL and PSTLCL filters. It can be seen that in comparison with the LCL filter the harmonic currents in the PST-LCL filter have been considerably reduced. Also, the total harmonic distortion in the LCL filter is $4.15 \%$, while in the PST-LCL it decreased to $1.94 \%$.
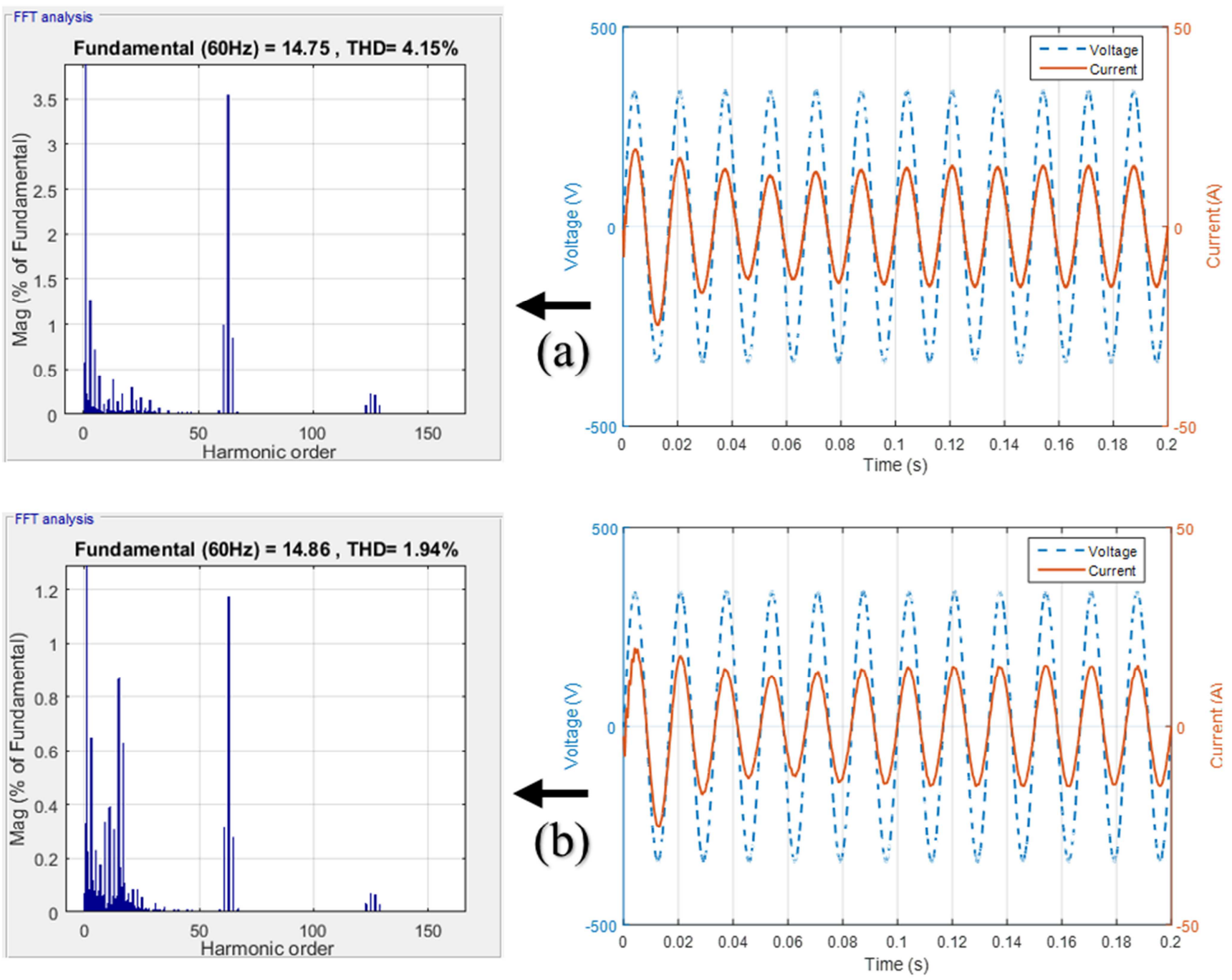

Figure 8. Case A. Currents injected into grid-FFTs and waveforms: (a) LCL filter, (b) PST-LCL filter.

Table 2. Case study A.

\begin{tabular}{|c|c|c|c|}
\hline \multicolumn{4}{|l|}{ PV Array Trina Solar TSM-250PA05.08 } \\
\hline Irradiance $W / m^{2}$ & 730 & Max Power & 249.86 \\
\hline Temperature (Deg. $C^{0}$ ) & 27 & Cells per module (Ncell) & 60 \\
\hline Open Circuit Voltage VOC (V) & 37.6 & Short-Circuit Current (A) & 8.55 \\
\hline Voltage at maximum power point $\mathrm{Vmp}(\mathrm{V})$ & 31 & Current at maximum power point $\operatorname{Imp}(\mathrm{A})$ & 8.06 \\
\hline Light-generated current (A) & 8.58 & Shunt Resistance (Ohms) & 301.8 \\
\hline Diode Ideality Factor & 0.9977 & Parallel & 1 \\
\hline Series Resistance (Ohms) & 0.25 & Series & 14 \\
\hline \multicolumn{4}{|l|}{ Inverter Control } \\
\hline Power (KVA) & 3.5 & Frequency $(\mathrm{Hz})$ & 60 \\
\hline Primary voltage (Vrms LL) & 240 & DC voltage (V) & 400 \\
\hline
\end{tabular}




\begin{tabular}{llll}
\hline PV Array Trina Solar TSM-250PA05.08 & & & \\
\hline Output increment (mV) & 3 & Output limits (V) & {$[375,450]$} \\
Output increment (V) & 0.01 & Carrier frequency (Hz) & 3780 \\
DC Voltage Controller & 11 & Current Regulator & 0.13 \\
Proportional gain & 187 & Proportional gain & 6.8 \\
Integral gain & Integral gain & \\
\hline
\end{tabular}

\subsection{Case Study B}

Figure 9 illustrates the case study B. The 250-kW SunPower SPR-415E-WHT-D source consists of 88 seven-module strings. Specifications of this PV array are listed in Table 3. Two 4-nF stray capacitances are located directly after the PV cells. A DC link stabilizes the DC voltage supplying three VSIs. The bipolar PWM method is employed. The grid voltage is $249 \mathrm{~V} \mathrm{[43].}$

Table 3. The case study B parameters.

\begin{tabular}{llll}
\hline PV Array Trina Solar TSM-250PA05.08 & & & \\
\hline Irradiance $\left(W / m^{2}\right)$ & 950 & Max Power (W) & 414.801 \\
Temperature (Deg. C) & 43 & Cells per module (Ncell) & 128 \\
Open Circuit Voltage VOC (V) & 85.3 & Short-Circuit Current (A) & 6.09 \\
Voltage at maximum power point Vmp (V) & 72.9 & Current at maximum power point Imp (A) & 5.69 \\
Light-generated current IL (A) & 6.09 & Shunt Resistance Rsh (Ohms) & 419.8 \\
Diode Ideality Factor & 0.9977 & Parallel & 88 \\
Series Resistance Rs (Ohms) & 0.25 & Series & 7 \\
Dc Link \& Stray Capacitance & & & $2.87 \mathrm{e}-3$ \\
Stray Capacitance & & DC Link & 425 \\
Capacitance (F) & $4 \mathrm{e}-9$ & Capacitance (F) & 60 \\
Inverter Control & & Capacitor initial voltage (V) & 480 \\
Power (KVA) & 250 & & {$[357,583]$} \\
Primary voltage (Vrms LL) & $25 \mathrm{~K}$ & Frequency (Hz) & 1980 \\
Secondary voltage (Vrms LL) & 249.8 & DC voltage (V) & \\
Output increment (V) & 0.01 & Output limits (V) & 0.25 \\
DC Voltage Controller & & Carrier frequency (Hz) & 18 \\
Proportional gain & 1.5 & Current Regulator & \\
Integral gain & 387 & Proportional gain & \\
\hline
\end{tabular}

\section{Inverter Control}

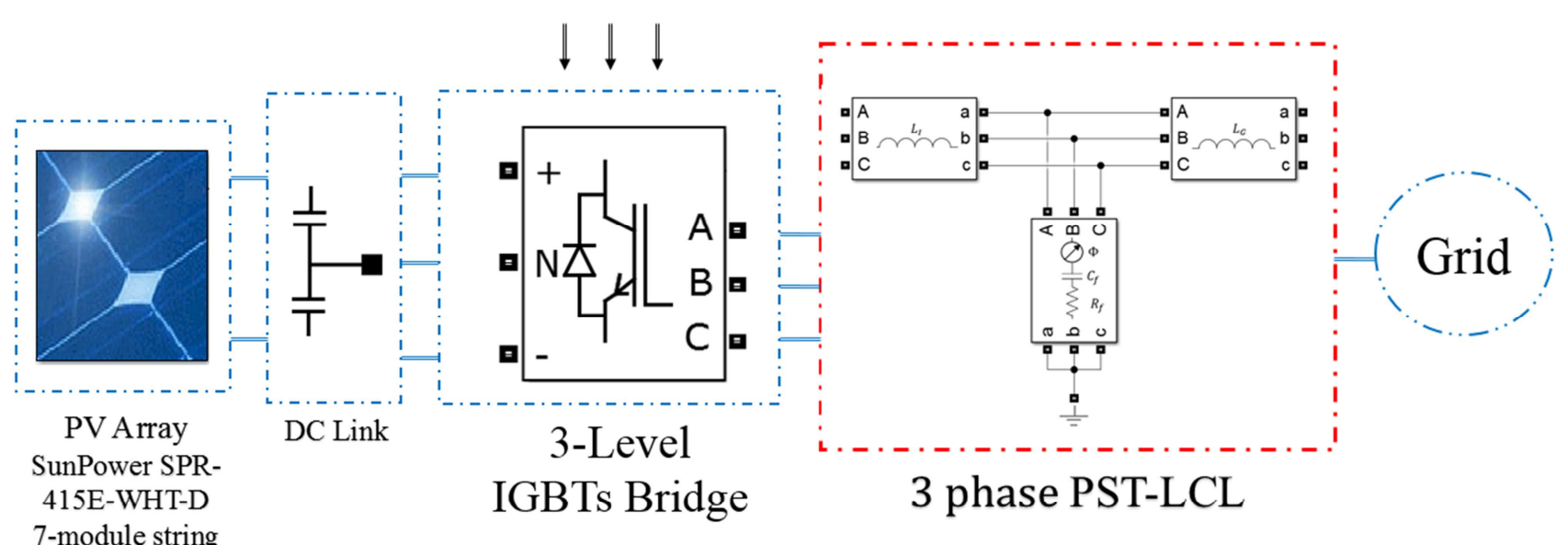

Figure 9. System in Case Study B.

Grid structure in case study B is shown in Figure 10. Table 4 lists specifications of the grid. Comparative FFT analysis for the LCL and PST-LCL filters is illustrated in Figure 11. The step-by-step design of the PST-LCL is outlined subsequently. System specifications are: $P_{S}=P_{n}=250 \mathrm{~kW}$, $E_{n}=249 \mathrm{~V} \quad, \quad V_{D C}=482 \mathrm{~V} \quad, \quad f_{s w}=1980 \mathrm{~Hz}, \omega_{g}=$ $2 \pi .60 \mathrm{rad} / \mathrm{s}, x=0.05$, and $k_{a}=20 \%$, Consequently, the base impedance and capacitance are $Z_{s}=0.25 \Omega$, and
$C_{B}=10.6 \mathrm{mF}$. Assuming the $10 \%$ allowed ripple, Eq. (15) yields $L_{I}=1.36 \mathrm{mH}$. In order to be within the limit of $5 \%$ of the base value of $\mathrm{CB}$, the maximum capacitor value, $\mathrm{Cf}$, is set to $0.53 \mathrm{mF}$. For the desired attenuation factor, $L_{G}$ is found from Eq. (19) to be $0.073 \mathrm{mH}$. Substituting the calculated parameters of $L_{I}, C_{f}$, and $L_{G}$ into Eq. (21) gives $\omega_{\text {res }}=$ $5218 \mathrm{~Hz}$, which meets condition (22). Eq. (23) determines the damping resistance $R_{f}=0.12 \Omega$. Angle $\Phi$ equals $40^{\circ}$, 
making $\delta_{b}=3.47^{0}$. The phase angle of the $C_{f}-R_{f}$ branch is $\left(-51.64^{0}\right)$ and, from Eq. (24), the phase angle of the PST is $\left(-55.11^{0}\right)$.

The THD in presence of the LCL filter is $5.75 \%$, and it decreases to $3.6 \%$ for the PST-LCL one. Figure 11 also shows waveforms of voltage and current in the inverter. It can be observed that harmonic currents in the later filter have been considerably decreased. It should be mentioned that in power system, along all advantages of using the PST, it is not inexpensive and it is only used if it is economical. Therefore, the main application of the PST is in power flow (or loop flow) control or protection.

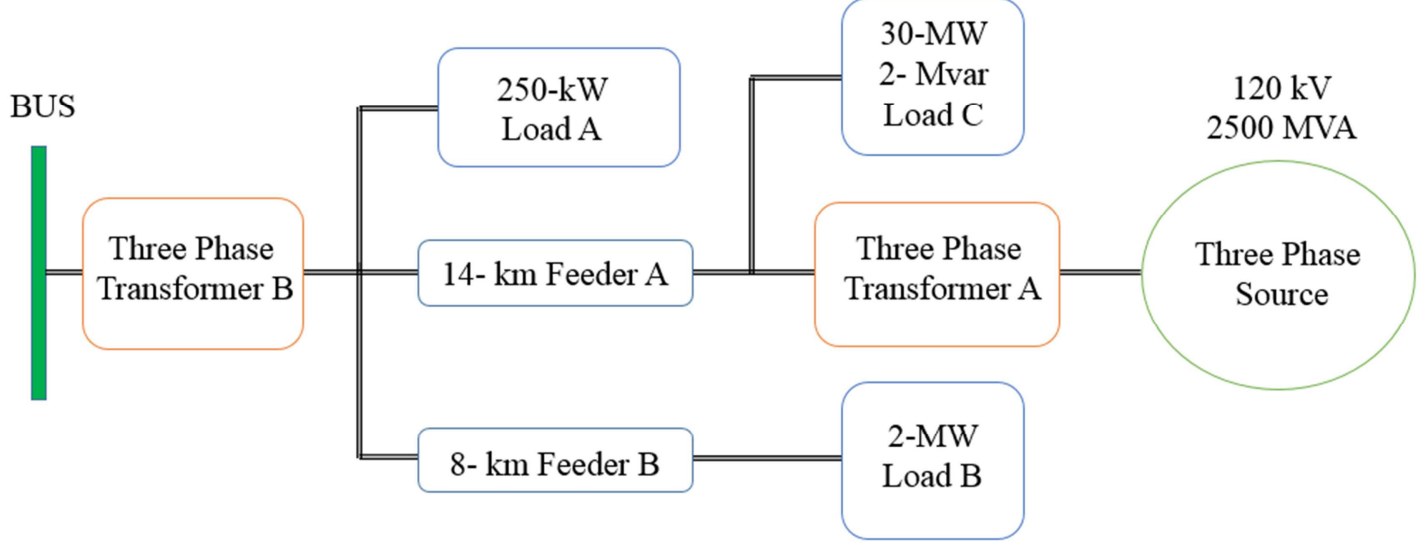

Figure 10. Grid structure in case study B.
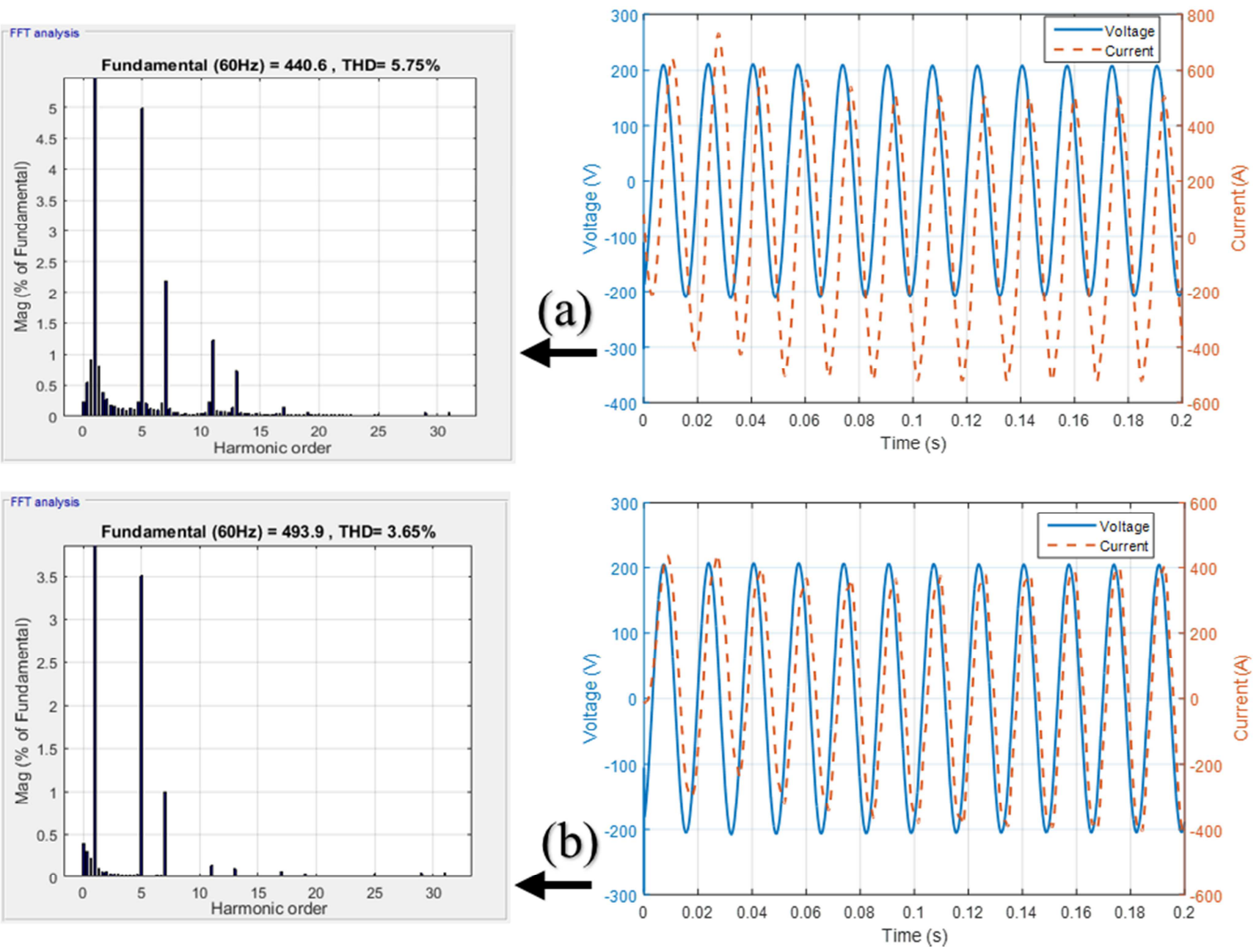

Figure 11. Case B. Currents injected into grid-FFTs and waveforms: (a) LCL filter, (b) PST-LCL filter. 
Table 4. The specification of the grid in case study $B$.

\begin{tabular}{|c|c|c|c|}
\hline \multicolumn{4}{|l|}{ Three Phase Source } \\
\hline Phase-to-phase rms voltage (KV) & 122.4 & 3-phase short-circuit level at base voltage (MVA) & 2500 \\
\hline Base voltage rms (KV) & 120 & $\mathrm{X} / \mathrm{R}$ ratio & 7 \\
\hline \multicolumn{4}{|l|}{ Three Phase Transformer A $(Y / \Delta)$} \\
\hline \multicolumn{4}{|c|}{ Winding 1 ( V1 rms [120 KV], R1 (pu) [0.0003], L1 (pu) [0.08]) } \\
\hline \multicolumn{4}{|c|}{ Winding 2 ( V2 rms [25 KV], R2 (pu) [0.0003], L2 (pu) [0.08]) } \\
\hline Load A: $250 \mathrm{KW}$ & Load B: 2 MW & Load C: $30 \mathrm{MW}$ and 2 Mvar & \\
\hline Nominal power (KVA) & 250 & Frequency $(\mathrm{Hz})$ & 60 \\
\hline \multicolumn{4}{|c|}{ Winding 1: ( V1 rms [25 KV], R1 (pu) [0.0012], L1 (pu) [0.03]) } \\
\hline \multicolumn{4}{|c|}{ Winding 2: ( V2 rms [249.8 V], R2 (pu) [0.0012], L2 (pu) [0.08]) } \\
\hline \multicolumn{4}{|c|}{ Feeder A: 14 Km R:0.115 (Ohms $/ \mathrm{km}), \mathrm{L}: 1.05(\mathrm{mH} / \mathrm{km}), \mathrm{C}: 11.33(\mathrm{nF} / \mathrm{km})$} \\
\hline \multicolumn{4}{|c|}{ Feeder B: 8 Km R:0.115 (Ohms/km), L: $1.05(\mathrm{mH} / \mathrm{km}), \mathrm{C}: 11.33(\mathrm{nF} / \mathrm{km})$} \\
\hline
\end{tabular}

Furthermore, the effective reactance of the phase-shifting transformer system varies with the tap setting of the load tap changer (LTC). In the extreme case of zero phase shift, the leakage impedance of the series winding will remain in the transmission path, whereas at the full rated phase shift, the effective impedance will be increased by the impedance of the regulating transformer. So, it requires frequent maintenance under full load. However, as mentioned before, the filter is designed to do not pass the main current through the filter. It means that, an inexpensive PST (not the ones used in power system) is just needed for this filter to just pass the harmonic current. Furthermore, the large reactors also need an iron core and the winding, so they resemble transformers, just smaller ones as they are tuned to higher frequencies. Power capacitors are expensive too. Therefore, the proposed filter may also reduce the required $\mathrm{L}$ and $\mathrm{C}$ size.

\section{Conclusion}

A novel approach to LCL filter design for gridinterconnected inverter systems has been presented. A phase shifting transformer is added into the regular LCL filter, making a PST-LCL filter with improved performance. Harmonic currents are significantly reduced improving operation of the involved utility grid. The presented fully controllable filter allows decreasing the current THD to a desired range. The comprehensive design technique of the PST-LCL filter has been described in detail.

\section{References}

[1] Rashid Niaz Azari, Mohammad Amin Chitsazan, Iman Niazazari. Optimal Recloser Setting, Considering Reliability and Power Quality in Distribution Networks. American Journal of Electrical Power and Energy Systems. Vol. 6, No. 1, 2017, pp. 1-6.

[2] M. A. Chitsazan, M. Sami Fadali, Amanda K. Nelson, A. M Trzynadlowski, "Wind speed forecasting using an echo state network with nonlinear output functions", American Control Conference (ACC), 2017 IEEE, pp. 5306-5311, May. 2017.

[3] F. Blaabjerg, T. Teodorescu, M. Liserre, and A. V. Timbus, "Overview of control and grid synchronization for distributed power generation systems," IEEE Trans. Ind. Electron., vol. 53, no. 5, pp. 1398-1409, Oct. 2006.
[4] V. Salas and E. Olías, "Overview of the state of technique for PV inverters used in low voltage grid-connected PV systems: Inverters above $10 \mathrm{~kW}$," Renew. Sustain. Energy Rev., vol. 15, no. 2, pp. 1250-1257, Feb. 2011.

[5] J. He, Y. Li, and M. S. Munir, "A flexible harmonic control approach through voltage-controlled DG-grid interfacing converters," IEEE Trans. Ind. Electron., vol. 59, no. 1, pp. 444-455, Jan. 2012.

[6] F. Bouchafaa, D. Beriber, and M. S. Boucherit, "Modeling and control of a grid connected PV generation system", in Proc. MED'10, Marrakesh, Morocco, pp. 315-320, Jun. 2010.

[7] M. Liserre, F. Blaabjerg, and S. Hansen, "Design and control of an LCLfilter-based three-phase active rectifier", IEEE Trans. Ind. Appl., vol. 41, no. 5, pp. 1281-1291, Sep./Oct. 2005.

[8] V. Blasko and V. Kaura, "A novel control to actively damp resonance in input LC filter of a three-phase voltage source converter", IEEE Trans. Ind. Appl., vol. 33, no. 2, pp. 542550, Mar./Apr. 1997.

[9] Y. Tang, S. Member, P. C. Loh, P. Wang, and F. H. Choo, "Generalized design of high performance shunt active power filter with output LCL filter", IEEE Trans. Ind. Electron., vol. 59, no. 3, pp. 1443-1452, Mar. 2012.

[10] IEEE Recommended Practices and Requirements for Harmonic Control in Electrical Power Systems, IEEE Std 5191992, 1993.

[11] IEEE Standard Conformance Test Procedures for Equipment Interconnecting Distributed Resources with Electric Power Systems, IEEE Std 1547.1-2005, 2005.

[12] M. Bojrup, "Advanced Control of Active Filters in a Battery Charger Application", Lund University of Technology, Lund, Sweden, PhD thesis, 1999.

[13] M. Lindgren, "Modelling and Control of Voltage Source Converters Connected to the Grid", PhD thesis, Chalmers University of Technology, Goteborg, Sweden, 1998.

[14] Y. Tang, P. Loh, P. Wang, F. Choo, F. Gao, and F. Blaabjerg, "Generalized design of high performance shunt active power filter with output LCL-filter", IEEE Trans. Ind. Electron., vol. 59, no. 3, pp. 1443-1452, Mar. 2012.

[15] F. Huerta, D. Pizarro, S. Cobreces, F. J. Rodriguez, C. Giron, and A. Rodriguez, "LQG servo controller for the current control of LCL grid connected voltage-source converters," IEEE Trans. Ind. Electron., vol. 59, no. 11, pp. 4272-4284, Nov. 2012. 
[16] T. C. Y. Wang, Z. Ye, G. Sinha, and X. Yuan, "Output filter design for a grid-interconnected three-phase inverter", in Proc. PESC'03, Acapulco, Mexico, pp. 779-784, Jun. 2003.

[17] J. R. Espinoza, G. Joos, E. Araya, L. A. Moran, and D. Sbarbaro, "Decoupled control of PWM active-front rectifiers using only dc bus sensing", in Proc. of IAS 2000 Conf., Rome, Italy, pp. 2169-2176, Oct. 2000.

[18] P. Channegowda and V. John, "Filter optimization for grid interactive voltage source inverters", IEEE Trans. Ind. Electron., vol. 57, no. 12, pp. 4106-4114, Dec. 2010.

[19] A. M. Hava, T. A. Lipo, and W. L. Erdman, "Utility interface issues for line connected PWM voltage source converters: a comparative study", in Proc. of APEC '95, Dallas (USA), pp. 125-132, March 1995.

[20] S. Chandrasekaran, D. Borojevic, and D. K. Lindner, "Input filter interaction in three phase AC-DC converters", in Proc. of PESC 99, Charleston (USA), vol. 2, pp. 987-992, Jun./Jul. 1999.

[21] M. A. Chitsazan, A. M Trzynadlowski, "State estimation of power systems with interphase power controllers using the WLS algorithm", Energy Conversion Congress and Exposition (ECCE), 2016 IEEE, pp. 1-5, Sep. 2016.

[22] M. A. Chitsazan, M. S. Fadali, A. M Trzynadlowski, "State estimation of IEEE 14 bus with unified interphase power controller (UIPC) using WLS method", Energy Conversion Congress and Exposition (ECCE), 2017 IEEE, pp. 2903-2908, Oct. 2017.

[23] M. A. Chitsazan, A. M Trzynadlowski, "Harmonic mitigation in interphase power controllers using passive filter-based phase shifting transformer", Energy Conversion Congress and Exposition (ECCE), 2016 IEEE, pp. 1-5, Sep. 2016.

[24] V. Sarfi, H. Livani, "A novel multi-objective securityconstrained power management for isolated microgrids in allelectric ships", Electric Ship Technologies Symposium (ESTS), 2017 IEEE, pp. 148-155, Aug. 2017.

[25] V. Sarfi, I. Niazazari, and H. Livani, "Multiobjective fireworks optimization framework for economic emission dispatch in microgrids", North American Power Symposium (NAPS), 2016, pp. 1-6, Nov. 2016.

[26] U. N. Khan and T. S. Sidhu, "A phase-shifting transformer protection technique based on directional comparison approach", IEEE Trans. on Power Delivery, vol. 29, no. 5, pp. 2315-2323, Sep. 2014.

[27] J. Bladow and A. Montoya, "Experiences with parallel EHV shifting transformers", IEEE Trans. on Power Delivery, vol. 6, no. 3, pp. 1096-1100, July 1991.

[28] M. A. Chitsazan, G. Gharehpetian, and M. Arbabzadeh, "Application of voltage source convector in interphase power controller", in Proc. of WCECS'12, San Francisco, CA, vol. 2, pp. 1-6,. Oct. 2012.

[29] P. Bresesti, M. Sforna, V. Allegranza, D. Canever, and R. Vailati, "Application of phase shifting transformers for a secure and efficient operation of the interconnection corridors", in Proc. IEEE Power Eng. Soc. Gen. Mtg., Denver, CO, vol. 2, pp. 1192-1197, Jun. 2004.
[30] J. Verboomen, D. V. Hertem, P. H. Schavemaker, W. L. Kling, and R. Belmans, "Phase shifting transformers: principles and applications", in Proc. FPS'05, Amsterdam, Netherlands, pp. 1-6, Nov. 2005.

[31] A. Reznik, M. G. Simoes, A. Al-Durra, S. M. Muyeen, "Filter design and performance analysis for grid-interconnected systems", IEEE Trans. on Ind. Appl., vol. 50, no. 2, pp. 1225, 1232, March-April 2014.

[32] H. Cha and T.-K. Vu, "Comparative analysis of low-pass output filter for single-phase grid-connected photovoltaic inverter," in Proc. APEC'10, Palm Springs, CA, pp. 16591665, Feb. 2010.

[33] S. V. Araujo, A. Engler, B. Sahan, and F. Antunes, "LCL filter design for grid-connected NPC inverters in offshore wind turbines," in Proc. ICPE '07, Daegu, S. Korea, pp. 1133-1138, Oct. 2007.

[34] V. H. Prasad, "Average Current Mode Control of a Voltage Source Inverter Connected to the Grid: Application to Different Filter Cells", M. S. thesis, Dept. Elect. Eng., Virginia Polytech. Inst. State Univ., Blacksburg, VA, USA, 1997.

[35] R. W. Erickson, D. Maksimovic, Fundamentals of Power Electronics, 2nd Ed., Kluwer Academic Publishers, 2001.

[36] D. E. Rice, "A detailed analysis of six-pulse converter harmonic currents" IEEE Trans. Ind. Appl., vol. 30, no. 2, pp. 294-304, March/April, 1994.

[37] M. Grötzbach, and R. Redmann, "Line current harmonics of VS1-fed adjustable-speed drives," IEEE Trans. Ind. Appl., vol. 36, no. 2, pp. 683-690, March/April, 2000.

[38] C. Rech and J. R. Pinheiro, "Line current harmonics reduction in hybrid multilevel converters using phase-shifting transformers," in Proc. PESC'04, Aachen Germany, pp. 25652571, Jun. 2004.

[39] G. M. Carvajal, G. O. Plata, W. G. Picon, and J. C. C. Velasco, "Investigation of phase shifting transformers in distribution systems for harmonics mitigation", in Proc. PSC'14, Clemson, NC, pp. 1-5, Mar. 2014.

[40] S. Ratanapanachote, M. Kang, and P. N. Enjeti, "Autoconnected electronic phase-shifting transformer concept for reducing harmonic generated by nonlinear loads in electric power distribution system," in Proc. PESC'01, Vancouver, Canada, vol. 2, pp. 1030-1035, Jun. 2001.

[41] D. A. Paice, "Power Electronic Converter Harmonics Multipulse Methods for Clean Power”, IEEE Press, 1996.

[42] Mohammad Amin Chitsazan, Andrzej M. Trzynadlowski. A New Approach to LCL Filter Design for Grid-Connected PV Sources. American Journal of Electrical Power and Energy Systems. Vol. 6, No. 4, 2017, pp. 57-63.

[43] Mohammad Amin Chitsazan, Andrzej M. Trzynadlowski, Harmonic Mitigation in Three-Phase Power Networks with Photovoltaic Energy Sources, American Journal of Electrical Power and Energy Systems. Vol. 6, No. 5, 2017, pp. $72-78$. 